\title{
A GIS FOR URBAN SUSTAINABILITY INDICATORS IN SPATIAL PLANNING
}

\author{
E. STYLIANIDIS, N. KARANIKOLAS \& D. KAIMARIS \\ School of Urban-Regional Planning and Development Engineering, \\ Aristotle University of Thessaloniki, Greece.
}

\begin{abstract}
Urban development and alterations in local/urban/sub-urban expansion plans is usually based on the analysis of spatial indicators and how they induce the future development in a specific area. For this structural reason the alterations of urban plans mainly occur under a surface observation and analysis of the spatial characteristics. Examining the issue under a more comprehensive framework we also focus on other characteristics such as social and economic policies, health and education, transportation, commercial, etc. that dominate on the development. Thus, urban sustainability indicators from a broad spectrum of activities should be introduced during urban planning. This paper investigates and analyzes the use of such urban sustainability indicators in spatial planning through the use of geographical information systems (GIS) designed for this reason.

Keywords: GIS, spatial knowledge, sustainability indicators, urban/spatial planning.
\end{abstract}

\section{INTRODUCTION}

In the mid-90s, the European Commission prepared a report called 'European Sustainable Cities Report' [1]. In this report, the Commission recognized the need for sustainability indicators as a tool for quantifying the return of sustainability. Since sustainability is a rational policy objective, it is possible to measure whether we have hysteresis or progress. In addition, the World Bank uses indicators as performance measures. All institutions involved in indicators' definition appear to consent that indicators are a useful tool, both for assessing policy measures and policy making as well. In both cases, these organizations stress their limitations.

The use of sustainability indicators is capable of playing a catalytic role in supporting planners, decision, and policy makers as well as other relevant stakeholders to assess urban development on one hand, while on the other to endorse the planning and implementation of sustainable spatial policies.

Furthermore, the expansion and development (local) plans implemented in a more general (metropolitan) approach will also be supported and monitored. In addition, decision makers and more policy makers will be enabled to discard groundless and purblind individual demands and requests, often based on speculation and personal gains rather than the chase of durable sustainability and societal benefits.

The paper aims to introduce the integration of urban sustainability indicators into the spatial planning process through geographical information systems (GIS). An appropriate sustainability indicators framework set is introduced. Furthermore, the procedure continues throughout the design and development of the appropriate information technology infrastructure to support the update, monitoring, and reporting of these indicators. Finally, these indicators are used as an urban policy tool in the decision making process.

In section 2, an introduction in urban sustainability indicators is mentioned. The background information and the definition of an indicative proposed set of indicators, spread in various thematic areas (e.g. social, economy, environment, etc.), are explained. This set originates from the URBANGUARD project, which took place in Cyprus as an EU co-funded project via LIFE scheme. In this section, the spatial dimension of indicators is discussed while a proposed geodatabase model for 
indicators is given. The geodatabase model is based on the ESRI platform and the CASE (computeraided software engineering) tools are used for geodatabase schema generation. In section 3, the different aspects of GIS in spatial planning using indicators are analyzed; like for instance thematic mapping, spatial analysis, or decision making. The paper concludes with discussion of the different procedures, previously analyzed and discussed.

\section{INTRODUCING URBAN SUSTAINABILITY INDICATORS}

\subsection{Background information of urban sustainability indicators}

Sustainability is the existence of harmony for built and non-built environment into perpetuity. It is a continuous and safe trip, a non-stop effort for the achievement of environmental, socio-economic, and cultural goals.

An urban entity, such as a city/town, with sustainable characteristics, is one, which achieves the equilibrium between environmental, economic, and cultural evolution through the participation and contribution of the civil society. It is also fundamental to most descriptions of sustainability, the concept that in a sustainable world people's lives will be more integrated. The definition shows the linkage of four significant spheres of life: social, economic, environmental, and cultural. Multiple criteria analysis (MCA) has been used as a decision support tool for many applications, as it provides a systematic framework for evaluating various options [2].

This way, we can describe the interdependence of the social, economic, environmental, and cultural spheres as four interlocking circles, representing the social, economic, and environmental cultural domains (Fig. 1).

Indicators that are dedicated to sustainable planning and development are bits of information that sum up and illustrate characteristics of composite systems and are designed to make observable trends which are not otherwise directly perceptible [3]. Sustainability itself is a very complex concept

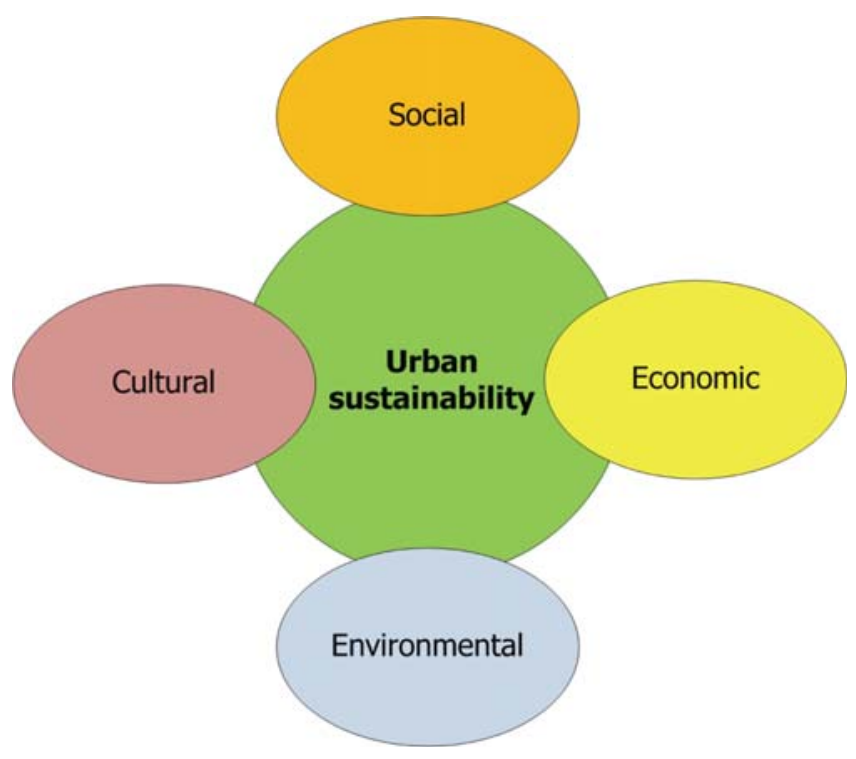

Figure 1: Spheres of urban sustainability. 
and involves environmental, economic, social, and cultural components, as well as several players, interests, and groups. At the end, sustainability indicators have been introduced to play a realistic and rational tool for making sustainability controllable for planners and policy makers. To analyze the spatiotemporal characteristics of human activities and interactions, many researchers used GIS as a platform to represent and explore their geographic data (e.g. [4-6]). When information needs to be exchanged over a larger scale, it is necessary to formalize the models used to describe an area to ensure that data are interpreted without ambiguity and communicated effectively. There is a great scientific discussion, which describes the main data models used for describing geographical phenomena, as discussed by several authors [7-10].

Nowadays, many projects and research studies include indicators in order to measure urban sustainability. Indicators are used in different scales and spaces. Many counties and regions use models of indicators to steer sustainable development. Different methods can be chosen to establish a range of indicators. In China, indicators' development has mainly taken place at an academic level. Although government has begun to pay more attention to the use of indicators, few indicators have been adopted as official criteria for the measurement of sustainable development at any administrative level [11].

The European Union proposed a system of indicators relevant to communities under the title of 'towards a local sustainability profile — European common indicators' [12].

Many people have contributed to the development of community sustainable indicators (e.g. [13-18]).

When assessing environmental conditions in the framework of sustainability the choice of indicators is a crucial step [19]. Several countries, such as New Zealand [20], Canada [21], Denmark [22], and The Netherlands [23] have taken this approach by measuring sustainability and development with the use of indicators and models.

\subsection{Definition and grouping of indicators}

Sustainability indicators are crucial in spatial analysis and planning and also in building urban development policy for two basic reasons:

- Indicators are expression of building consensus around the long-term goals set up by a (local) community;

- Indicators may exploit for the appraisal of the impact of the governmental or community actions in local and/or regional level.

The planning and definition of sustainability indicators is a hard, time-consuming, and continuous process. Under this process, the assessment of the existing situation, the community organizing, and development of new needs should outline the long-term sustainability vision. Participants in this process should be the relevant governmental services, the local authorities, and the local communities as they are represented by civil society in different expressions. All of them must have the chance to consider at all levels, away from the demands of implementation closing dates.

Indicators make available indication of circumstances or problems and thus may be qualitative or quantitative. Additionally, there are also restrictions as to how functional indicators may be. Indicators present a picture of a broader situation, but sometimes do not offer overall perception. For instance, if measuring the rainfall at the flat level, this measure does not give information how rainy it is at the hilly areas. Indicators can determine alterations over time; they do not calculate end objectives. For instance, when a car is driving at a speed of $90-120 \mathrm{~km} / \mathrm{h}$, one can calculate the acceleration but cannot estimate where the car would like to stop. 
Under this analysis, the indicators involved in urban development may fractionate in the following broader thematic areas: (1) social, (2) economy, (3) environment, (4) residential, (5) health, (6) education, (7) transport, (8) business, (9) tourism, (10) industry, (11) culture, and (12) sports. Alongside, the overall breakdown of specific indicators per thematic area provides the detailed framework. In Table 1, indicative examples are given to illustrate the picture of indicators for each one of the categories.

The interconnection of the different sustainability indicators exists, but not in all cases. This interrelation is more visible especially in similar or at least closely related thematic areas. Each case should be carefully examined via spatial analysis and documented metrics. Two examples are given to prove this assumption; one example with two indicators from the same thematic area and one example with two indicators from two different thematic areas.

Table 1: An indicative set of indicators from different thematic areas.

\begin{tabular}{|c|c|c|}
\hline Indicator name & Area & Description \\
\hline Unemployment rate & Social & $\begin{array}{l}\text { Unemployment rate is the ratio of } \\
\text { unemployed people to the labor force }\end{array}$ \\
\hline GDP & Economy & $\begin{array}{l}\text { GDP: total value of goods and services } \\
\text { produced during a period of time }\end{array}$ \\
\hline $\begin{array}{l}\text { Number of protected } \\
\text { landscapes }\end{array}$ & Environment & $\begin{array}{l}\text { Total number of protected landscapes within a } \\
\text { study area (exceptional aesthetic value sites, } \\
\text { natural monuments, water courses, coastal } \\
\text { zones, forests) }\end{array}$ \\
\hline Population density & Residential & $\begin{array}{l}\text { Total population size of a specific study area } \\
\text { divided by its surface area }\end{array}$ \\
\hline $\begin{array}{l}\text { Ratio of public hospitals to } \\
\text { the total population }\end{array}$ & Health & $\begin{array}{l}\text { The ratio of the total number of existing } \\
\text { public hospitals to the total population } \\
\text { within a study area }\end{array}$ \\
\hline Number of libraries & Education & The number of libraries within a study area \\
\hline Road space per inhabitant & Transport & $\begin{array}{l}\text { The area occupied by covered roads within a } \\
\text { study area }\end{array}$ \\
\hline $\begin{array}{l}\text { Percentage of developed } \\
\text { commercial space }\end{array}$ & Business & $\begin{array}{l}\text { The percentage of commercial development } \\
\text { as per the authorities definitions }\end{array}$ \\
\hline Tourist bed density & Tourism & $\begin{array}{l}\text { The ratio of the total number of existing beds } \\
\text { used for tourist accommodation per square } \\
\text { meter of the reference tourist area }\end{array}$ \\
\hline $\begin{array}{l}\text { Percentage of utilization of } \\
\text { designated industrial areas }\end{array}$ & Industry & $\begin{array}{l}\text { The percentage of utilization of the } \\
\text { designated industrial areas as per the } \\
\text { authorities definitions }\end{array}$ \\
\hline Number of ancient monuments & Culture & $\begin{array}{l}\text { The number of ancient monuments within a } \\
\text { study area }\end{array}$ \\
\hline Number of sports facilities & Sports & $\begin{array}{l}\text { Total number of sports facilities (indoor and } \\
\text { outdoor facilities which provide public } \\
\text { access to sports infrastructure) }\end{array}$ \\
\hline
\end{tabular}


- First example: the indicator 'unemployment rate by sex' belongs to the area 'social-economic area' and the measurement considers the 'percentage' (\%). On the other hand, indicator 'average household income' belongs to the same area and its measurement is considered in 'euro' $€$ ). It is obvious that the two indicators should be considered as potential interrelated and the verification should be examined through spatial analysis on the different spatial levels of interest (Fig. 3).

- Second example: the indicator 'average household income' belongs to the area 'socio-economic area' and its measurement is considered in euro $(€)$. On the other hand, indicator 'population density in each environmental area...' belongs to a different thematic area, i.e. 'residential' and its measurement is considered in euro (€). It seems to be evident that the two indicators should be considered as potential interrelated since in most cases worldwide, high household income reflects low density population and vice versa. In any case the verification should be examined through spatial analysis and documented metrics.

At this point, indicators' selection process deserves further investigation. The urban area has many systems and components, some of which are shown in Table 1 . Thus, here seems to be a key dilemma for researchers, planners, and policy makers regarding the indicators' selection process. From one side, there is the option of using a small and flexible scheme of urban sustainability indicators to facilitate the collection procedure of the required data, while on the other a comprehensive indicator system that includes a large number of indicators from different categories.

Figure 2 illustrates an indicative example of a database. This example originates from the URBANGUARD project; a LIFE project co-funded by the European Commission, held in Nicosia, Cyprus

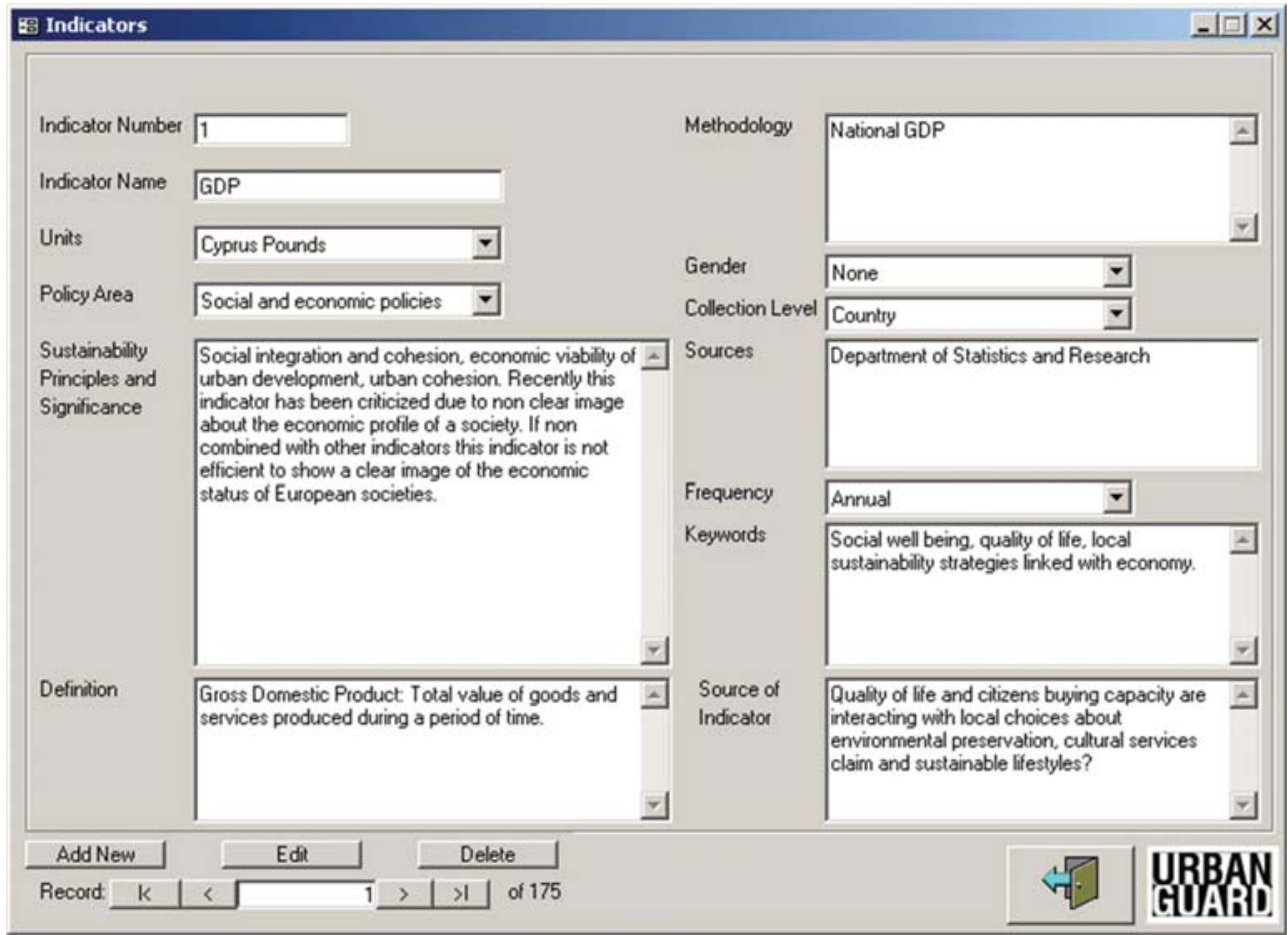

Figure 2: Sustainability indicators' database from URBANGUARD project. 
and led by the Department of Planning and Housing, Ministry of Interior, Republic of Cyprus. In this specific project, 175 different indicators have been selected; a significant number of urban sustainability indicators for both inland and coastal cities have been classified into 12 different categories.

The mission of the Department of Planning and Housing is the regulation of urban and spatial development in Cyprus, having as reference sustainability and public interest. The Department of Planning and Housing is responsible for the preparation of development plans and studies, and which are implemented considering the urban planning audit. Through a series of projects and incentives, the Department of Planning and Housing is also responsible for upgrading and conservation of the natural and built environment within the context of sustainable development.

In the case of indicators, the Department of Planning and Housing introduced a set of 175 different indicators. These indicators are subjected to the urban planning audit and consists an outcome of a consensus procedure not only within the Department at local level but also in the other districts of the island. This is the reason why this significant number of urban sustainability indicators refers both inland and coastal cities and categorized into 12 different categories. For instance, tourism and consequently the relevant indicators refer to an urban area, such as the capital, may not even have neither the same meaning nor content with the indicators in coastal areas where tourism development is a key to local development.

\subsection{Spatial dimension}

By nature, sustainable development is temporal as implied by the term 'development'; since development is not a static procedure. Whether sustainable or not, by nature again, development has a spatial reference, since all developments are taking place at certain places on Earth, which can be represented by Cartesian coordinates (X, Y, Z). Thus, for a region, whether a municipality, district, periphery, or country, there can be important spatial heterogeneity or dissimilarities, which in many cases ought to have particular consideration. Astonishingly, the spatial dimension has often been ignored or been given low priority by groups planning environmental or sustainability indicators. Nowadays, with the expansion of GIS and spatial databases, nobody denies the necessity of using these technologies in describing, analyzing, and understanding spatial phenomena.

The spatial analysis of sustainability indicators is based on different levels of spatial reference. Using a coarse-to-fine approach, the analysis starts from the street level to country level. This approach seems to be evident as one data refer to a street level and the other refer to a country level. For example, the gross domestic product (GDP) more probably refers to the country level rather than street level. On the other hand, population may be countable both on street and country level. Thus, in such analysis the different spatial levels of interest are: street, survey area, environmental area, parish, municipality, region, and country.

Figure 3 illustrates the different spatial reference levels. The fundamental entity for this analysis is the survey area which is the area usually defined by the Statistical Service for the collection of census and other statistical data. Environmental area consists of the grouping of few survey areas and constitutes a vital spatial unit for planning reasons.

\subsection{Data collection}

Indicators have no use when data do not exist to define their quantitative component. Their values should refer and be valid for a specific period whereas the metadata is also valuable for the total assessment. 

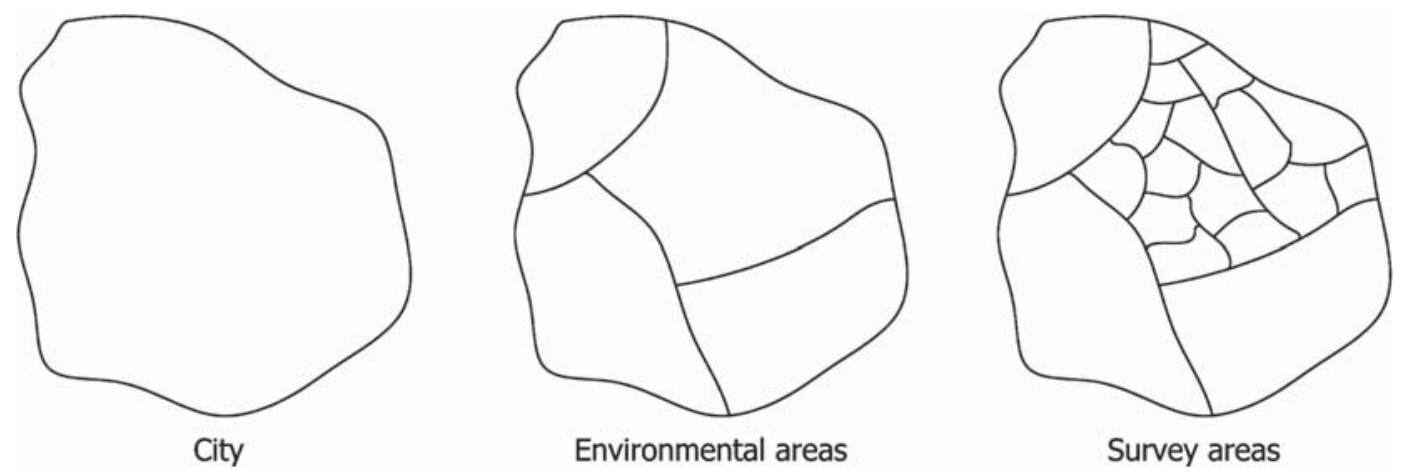

Figure 3: Different spatial levels of interest.

The sustainability of a neighborhood, region, or country is based on the governmental or local authorities and the civil society. In urban planning and broader in spatial development, these information technology tools are quite effective. But, what necessary, in any case, are data collection strategies as well as concepts for compiling, transforming, and interpreting existing data.

In regulated countries, organized systems and structures, primarily in public services, are possible through an organized data collection and management framework to achieve a comprehensive and updated dataset. A typical example of such a service is the Statistical Service that is responsible for a huge amount of data. This service collects a large amount of data both during the 10-year census and individual annual surveys. A decentralized information system, to collect, manage, and control information from other services (e.g. planning, environmental service, etc.) into a central information system managed by the Statistical Service, seems to be the ideal solution in an attempt to have both good data and data with the least possible cost.

\subsubsection{The role of governmental services and local authorities}

The governmental departments, agencies, bodies, and services as well as the local authorities are a powerful lever for the development of such a system of urban sustainability indicators. This is because they have the strong mechanism of the state, which has a wealth of data that often remains untapped.

Various agencies and organizations such as ministries (finance, labor, environment, public works, etc.), municipalities can and should contribute in the endeavor to develop such indicator system. What is often missing is the coordination of all these services; so this issue, in our view, should be organized and managed centrally and allocated to each department and agency. This option allows each player to play a major role in the whole system while at the same time is committed to assist in the collection and use of data, not only for its own interest but primarily for the benefit of society.

\subsubsection{The role of civil society}

In order to build strong, self-determined, sustainable local communities, the role of civil society in this case could be catalytic. The potential role of GIS is either a democratizing force or a disenfranchising force is a growing topic of conversation within the GIS community [24-27]). The optimum result occurs when local inhabitants, public representatives, academic researchers, and other stakeholders jointly work in a comprehensive, considerate, and open practice. The role of civil society may prove decisive in the collection process for sustainability indicators. There are cases where local residents have the opportunity to play a more effective role than the governmental services. 


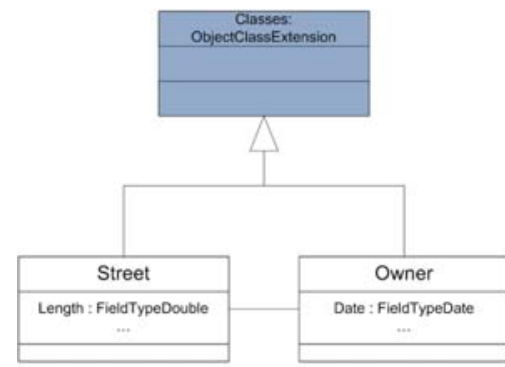

Create UML Model

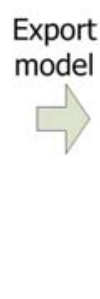

Metadata Interchange (XMI)

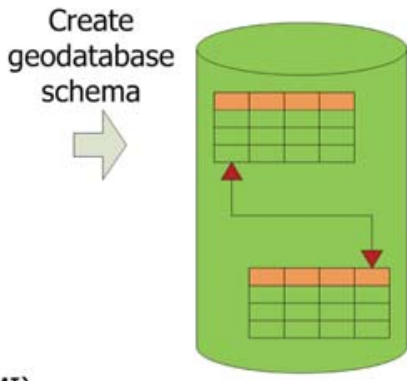

Figure 4: The road map from UML to the geodatabase scheme.

Every city needs a vision. GIS can prove to be a systematic approach of e-government in a more citizen-centric approach. We always have to remember that GIS is not just a 'tool designed to solve one aspect of a particular problem - that of translating spatially referenced empirical information into a spatial language to enable cartographic representation of patterns and relationships, and of analyzing the nature of these relationships'; rather, 'the development of GIS, or any other, technology is a social process' [28]. The environmental groups in cities are central to reach this vision. For every group in civil society, in every city, it is important to recognize that the real visions leading to transformations will diverge from the governmental or market ones. Both, the civil society and the local communities have the choice to vision their prospect and future development, considering outside of the model. These groups are not predisposed to the capital interest while market is necessary for changing cities.

\subsection{A geodatabase for indicators}

GIS is used as a tool for management and visualization of urban sustainability indicators playing with different policy scenarios. The geodatabase data model by ESRI is used to store and model the urban sustainability indicators. ESRI CASE tools is used to generate the geodatabase structure (schema). The CASE tools subsystem allows the user to create blueprints of the geodatabase structure using a graphical language, i.e. the Unified Modeling Language (UML). By using class diagrams, all geodatabase elements can be represented, such as feature datasets, feature classes, and tables. Therefore, the Microsoft Visio is a tool that could be used for UML model construction, then exporting that to an XML Metadata Interchange (XMI) file and finally use CASE tools to import the XMI into ArcCatalog to generate the geodatabase schema.

This method of building a geodatabase allows the design and structure to be easily shared and modified as the project grows. This design method provides enhanced facilities for the documentation and database customization. Figure 4 illustrates the road map from UML to geodatabase scheme, following the specific strategy.

\section{THE GIS FOR SPATIAL PLANNING USING INDICATORS}

The use of a GIS in spatial planning has grown gradually since the 1960s as discussed by several authors $[29,30]$. As a result, an extensive collection of GIS applications in various spatial planning 
tasks has grown such as land use, transportation, economic development, etc. GIS has support both in administrative and decision-making tasks in planning by providing a distinctive approach of viewing and analyzing spatial data by presenting it in a geographical layout. Full color maps expose patterns, relationships, and correlations that allow users of data - planners and decision makers - to view information in a new perspective.

The novel knowledge, responsiveness, and recognition of GIS together with lower costs for software and hardware - even with open-source GIS solutions - have assisted greatly in disseminating the implementation of GIS in planning (public or local authorities) organizations.

Recently, an important GIS application area concerns urban (spatial) planning using a framework of sustainability indicators. Urban planning is considered to be an important approach for towns/ cities that are undertaking regeneration policies either for the towns'/cities' centers or for urban neighborhoods. GIS is able to significantly make possible such strategic planning throughout data analysis, representation, and visualization capabilities; especially when using sustainability indicators. In this context, GIS application is very supportive not only when data analysis occurs, but also when communicating the GIS outcomes to the citizens in the course of its visualization and representation techniques.

\subsection{Thematic mapping}

Since all data for indicators are stored on the database, GIS is offering proper tools for thematic mapping of all the geographic phenomena and relations. Thematic mapping is acting as the output of spatial analysis on specific queries set to the system. Based on the stored data, maps are illustrating the picture of the query and thus the results are thematic maps. An overview of the thematic maps from the sustainability indicators GIS is given below. This synopsis is not exhaustive; it is merely indicative of the content of this system.

A choropleth map is a thematic map in which areas (like for instance environmental or survey areas), depending on the spatial reference of existing data, are shaded or patterned in proportional to the measurement of the statistical variable displayed on the map. An indicative sample is given in Fig. 5, in which population density is portrayed, considering as spatial reference unit of the environmental area.

Another indicator is related to points. An example is given in Fig. 6, where population is portrayed with the use of proportional symbols. In this case, we consider the survey area as the spatial reference unit.

\subsection{Spatial analysis and decision making}

Planners and decision or policy makers should keep in mind the following points when planning on the urban environment: what to adjust, what to organize, what to change, and what to leave as is. The transformation of activities required by sustainable development put forward potentials for realizing better standards for quality of life. A key issue in this process is the urban sustainability indicators. By analyzing these indicators under their spatial reference, planners and decision makers are encoding numbers, percentages, etc. into digital representations which in turn help to further analyze and finally shape the proposals and recommendations.

GIS cannot be considered as the solution to spatial (sustainable) planning but a powerful tool facilitating the decision-making process. GIS technology in the appropriate hands can be a vehicle for different application scenarios: indicatively in effective and sustainable environmental management [31], in tourism planning [32], urban transport ecological footprint analysis [33], etc. 


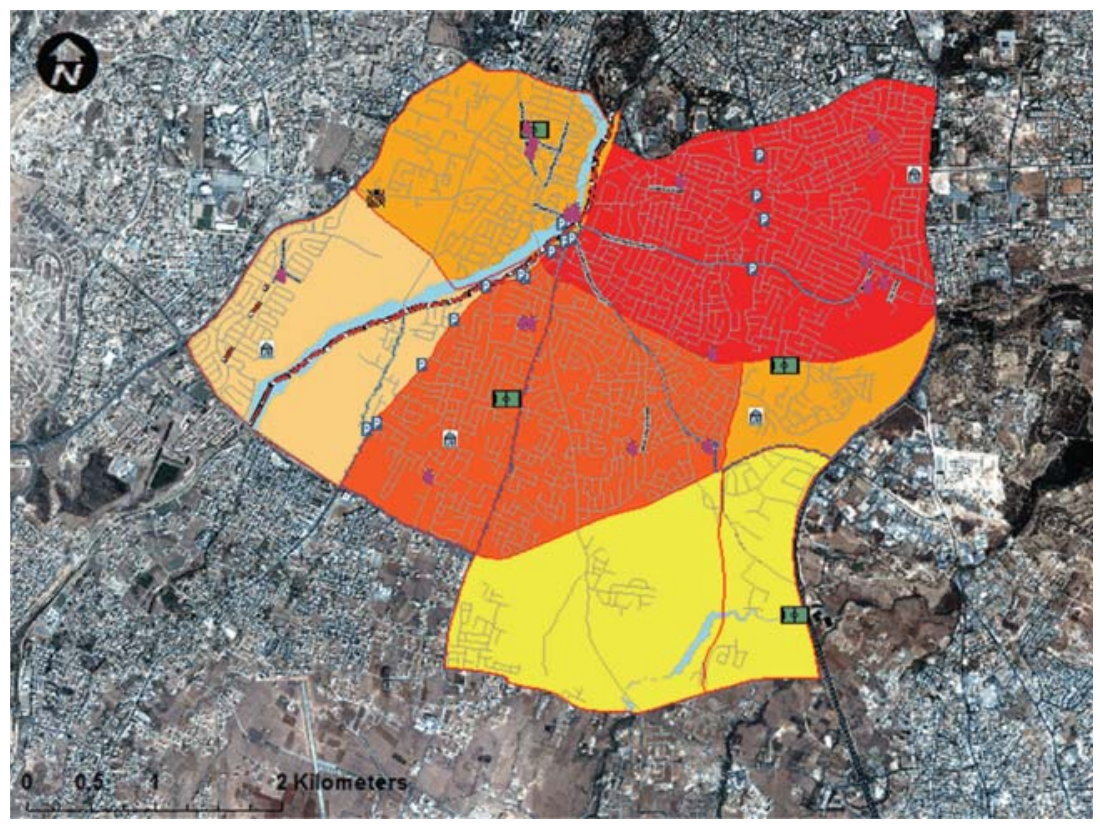

Figure 5: A choropleth map for population density in Nicosia, Cyprus (environmental area).

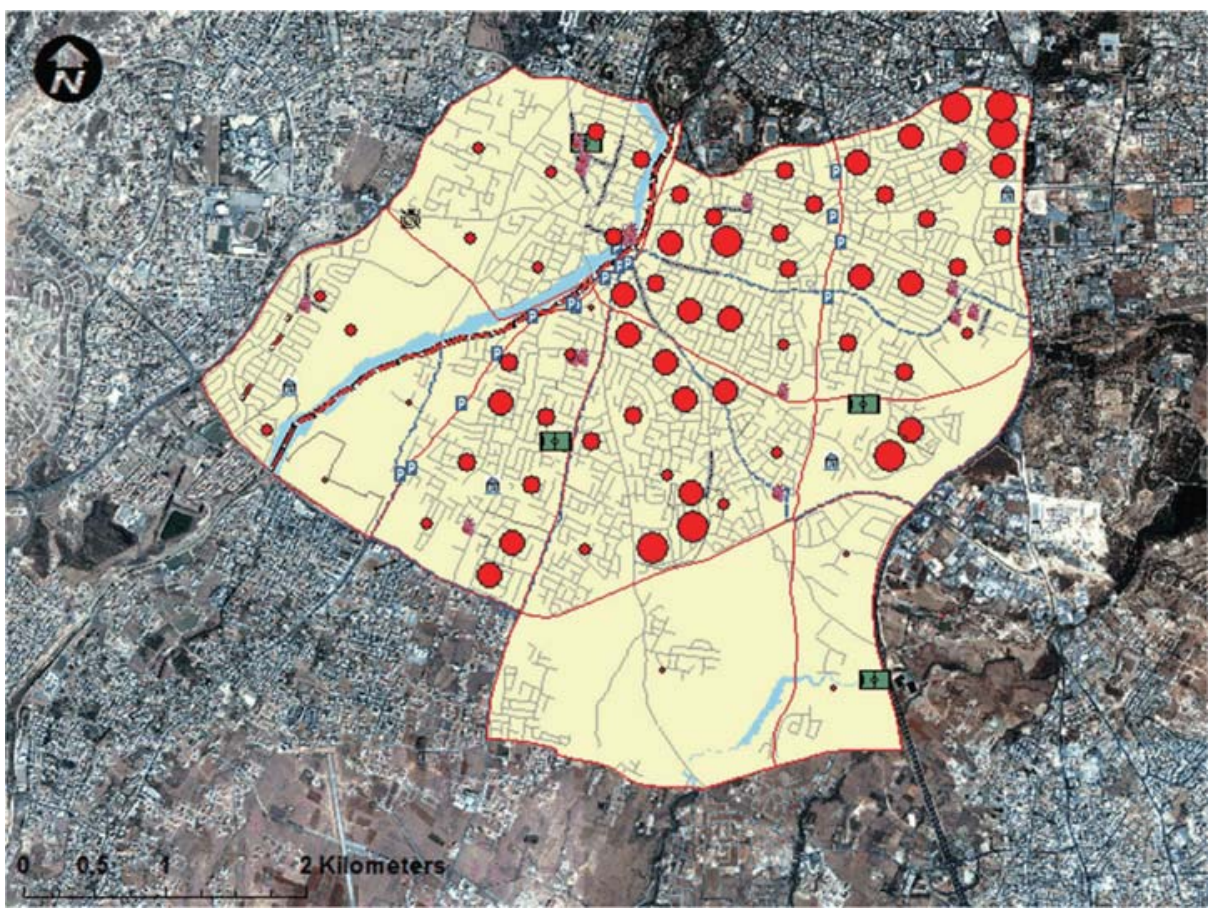

Figure 6: Proportional symbols thematic map of population in Nicosia, Cyprus (survey area). 


\section{CONCLUSIONS}

The paper discusses the use of sustainability indicators in spatial planning. In the research conducted during URBANGUARD project, a project co-funded by the European Commission under the LIFE financing scheme, a sustainability indicators' geodatabase was developed to support a dedicated GIS. The GIS is further supporting the decision-making process via the urban sustainability indicators. The system works when appropriate data are inserted into the system, to make available important information in the spatial planning process.

The development of highly sophisticated spatial process modeling techniques, involving the modular and distributed amalgamation of GIS and modeling software capabilities is progressing rapidly. At the same time, research is continuing into GIS interoperability, representing the unrestricted exchange of data and process [34].

The process of drafting specific and measurable urban sustainability indicators is not an easy task. On one hand, the indicators should be based on fundamental scientific principles while on the other they should be adapted to local and specific conditions in which they are applicable. The indicators should have spatial reference in order to contribute in spatial planning and decision making, while on the other hand data used for generating indicators should be collected and coded on an easy way.

Spatial planning concerns a decisive and strategic vision about space and places as the basis for action and interference. Spatial planning goes beyond conventional land use planning to accumulate and integrate policies for the development and make use of land with other policies and programs which influence the character of places as well as their functionality.

With the aim of obtaining an extensive range of views over issues concerning spatial planning strategies in the urban space, the problems of defining spatial sustainability indicators, and the prospects of developing a strategy for monitoring the spatial planning outcomes, a specific spatial framework with sustainability indicators was designed (Fig. 7).

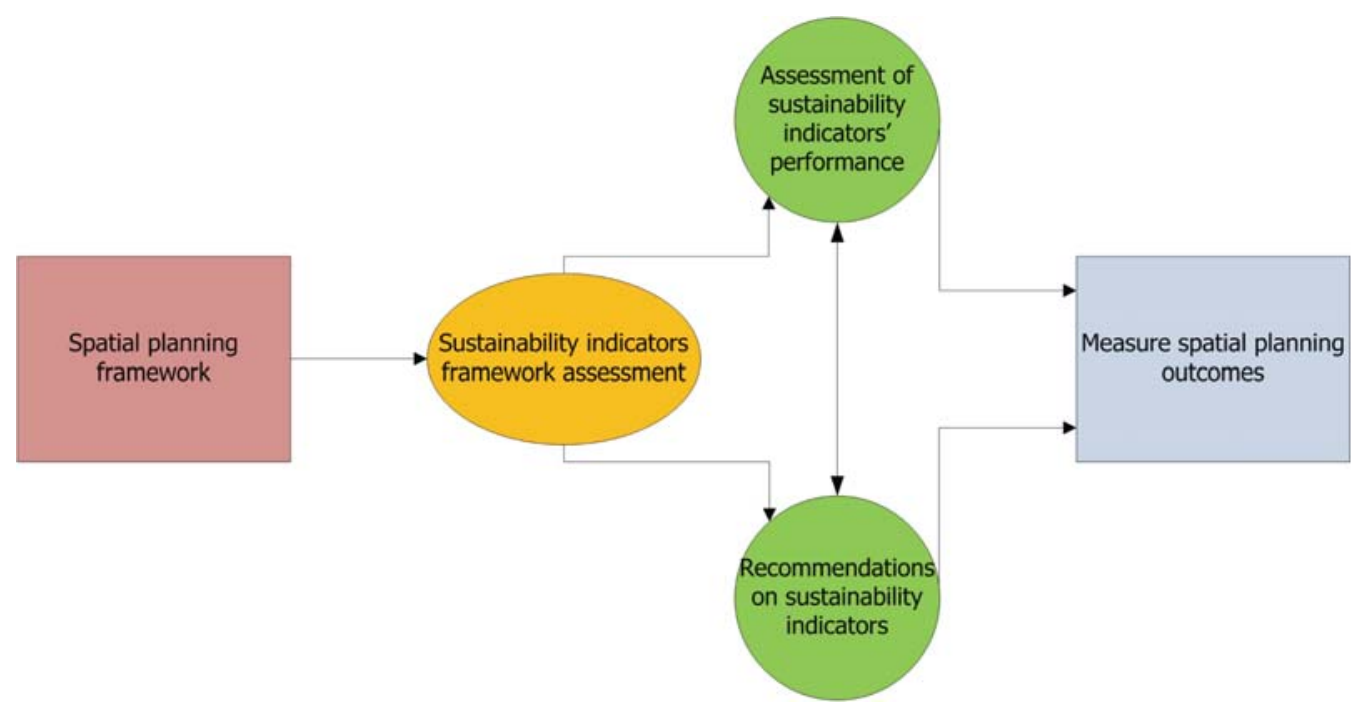

Figure 7: Spatial planning framework with sustainability indicators. 
So as Fig. 7 illustrates schematically, a sequential methodological approach was devised to address the research in spatial sustainability indicators. The steps are to:

- Develop a strategic spatial planning framework by identifying the main objectives and enviable outcomes of sustainable spatial planning in urban space.

- Set out an assessment framework for urban sustainability indicators by specifying their meaning, the main criteria, and the methodological framework to be used as a specific outcome indicator.

- Start out an assessment for the performance of urban sustainability indicators in the different thematic areas; this action involves a review of all relevant indicators and existing datasets.

- Make recommendation for a final urban sustainability indicators framework and its principles.

\section{REFERENCES}

[1] European Commission, DG XI, European Sustainable Cities. Brussels: European Commission, 1996.

[2] Graymore L.M.M., Wallis M.A. \& Richards J.A., An Index of Regional Sustainability: A GISbased multiple criteria analysis decision support system for progressing sustainability, Ecological Complexity, 6(4), pp. 453-462, 2009. doi:http://dx.doi.org/10.1016/j.ecocom.2009.08.006

[3] Hammond, A., Adriaane, A., Rodenburg, E., Bryant, D. \& Woodward, R., Environmental Indicators: a Systematic Approach to Measuring and Reporting on Environmental Policy Performance in the Context of Sustainable Development, WRI, USA, 1995.

[4] Shaw, S-L. \& Wang, D., Handling Disaggregate Spatiotemporal Travel Data in GIS. GeoInformatica, 4(2), pp. 161-178, 2000. doi:http://dx.doi.org/10.1023/A:1009824122914

[5] Wang, D. \& Cheng T., A Spatio-temporal Data Model for Activity-based Transport Demand Modelling. International Journal of Geographical Information Science, 15(6), pp. 561-585, 2001. doi:http://dx.doi.org/10.1080/13658810110046934

[6] Frihida, A., Marceau D. \& Thériault M., Spatio-temporal object-oriented data model for disaggregate travel behaviour. Transactions in GIS, 6(3), pp. 277-294, 2002. doi:http://dx.doi. org/10.1111/1467-9671.00111

[7] Couclelis, H., People manipulate objects (but cultivate fields): beyond the raster-vector debate in GIS. Theories and Methods of Spatio- Temporal Reasoning in Geographic Space, eds A.U. Frank, I. Campari \& U. Formentini, Springer Verlag: Berlin, pp. 65-77, 1992.

[8] Frank A.U. \& Campari I., Spatial Information Theory, Springer-Verlag: Berlin, 1993.

[9] Egenhofer, M.J. \& Herring, J.R., Categorizing Binary Topological Relations between Regions, Lines, and Points in Geographic Databases. Technical Report, Department of Surveying Engineering, University of Maine: Orono, 1991.

[10] Burrough, P.A. \& Frank, A.U., Geographic objects with indeterminate boundaries. Taylor \& Francis: London, 1996.

[11] Yuan, W., James, P., Hodgson, K., Hutchinson, S.M., Shi, C., Development of sustainability indicators by communities in China: a case study of Chongming County, Shanghai. Journal of Environmental Management, 68, pp. 253-261, 2003. doi:http://dx.doi.org/10.1016/S03014797(03)00063-X

[12] European Commission, Towards a local sustainability profile: European common indicators. Working Group on measuring, monitoring and evaluation in local sustainability, Expert Group on the urban environment. Office for Official Publication of the European Communities, 2000.

[13] Walter, G.R.\&Wilkerson, O.,Community sustainability auditing.Journal of EnvironmentalPlanning and Management, 41, pp. 673-682, 1998. doi:http://dx.doi.org/10.1080/09640569811362

[14] Valentin, A. \& Spangenberg, J.H., A guide to community sustainability indicators. Environmental Impact Assessment Review, 20, pp. 381-392, 2000. doi:http://dx.doi.org/10.1016/ $\underline{\text { S0195-9255(00)00049-4 }}$ 
[15] Von Euler, F., An objective indicator of functional integrity in avian communities. Forest Ecology and Management, 115, pp. 221-229, 1999. doi:http://dx.doi.org/10.1016/S0378-1127(98)00401-0

[16] Alexander, G., Information-based tools for building community and sustainability. Future, 32, pp. 317-337, 2000. doi:http://dx.doi.org/10.1016/S0016-3287(99)00100-7

[17] Kammerbauer, J., Cordoba, B., Escolan, R., Flores, S., Ramirez, V. \& Zeledon, J., Identification of development indicators in tropical mountainous regions and policy designs: an integrated community case study. Ecological Economics, 36, pp. 45-60, 2001. doi:http://dx.doi. org/10.1016/S0921-8009(00)00206-8

[18] Whitford, V., Ennos, A.R. \& Handley, J F., City form and natural process-indicators for the ecological performance of urban areas and their application to Merseyside, UK. Landscape and Urban Planning, 57, pp. 91-103, 2001. doi:http://dx.doi.org/10.1016/S0169-2046(01)00192-X

[19] Meadows, D., Indicators and Information Systems for Sustainable Development. Hartland Four Corners, VT: The Sustainable Institute, 1999.

[20] Ward, C.J., Environment Indicators for State of the Environment Reporting. Information Paper No. 21. Canterbury, New Zealand: Centre for Resource Management Press, 1990.

[21] Environment Canada, State of the Environment Reporting Indicators Task Force. A report on Canada's progress towards a national set of environmental indicators. State of the Environment Report, no. 91-1. Supply \& Services: Ottawa, 1991.

[22] Holten-Andersen, J., Christensen, N., Kristiansen, L.W., Kristensen, P. \& Lennarrt, E., The state of the environment in Denmark, Technical Report, No. 1. Arhus: National Environment Research Institute, 1998.

[23] Alberti, M. \& Parker, J., Indices of environmental quality: in search of credible measures. Environmental Impact Assessment Review, 11, pp. 110-136, 1991.

[24] Harris, T.M., Weiner, D., Warner, T. \& Levin, R., Pursuing Social Goals Through Participatory GIS: Redressing South Africa's Historical Political Ecology. Ground Truth, ed. John Pickles, Guilford Press: New York, pp. 196-222, 1995.

[25] Rundstrom, A.R., GIS, Indigenous Peoples, and Epistemological Diversity. Cartography and Geographic Information Systems, 22(1), pp. 45-57, 1995. doi:http://dx.doi. org/10.1559/152304095782540564

[26] Obermeyer, J.N. \& Pinto J.K., Managing Geographic Information Systems, Guilford Press: New York, 1994.

[27] Obermeyer, J.N., The Hidden GIS Technocracy. Cartography and Geographic Information Systems, 22(1), pp. 78-83, 1995. doi:http://dx.doi.org/10.1559/152304095782540609

[28] Sheppard, E., GIS and Society: Towards a Research Agenda. Cartography and Geographic Information Systems, 22(1), pp. 5-16, 1995. doi:http://dx.doi.org/10.1559/152304095782540555

[29] Harris, T. \& Elmes, G., The Application of GIS in Urban and Regional Planning: A Review of the North American Experience. Applied Geography, 13, pp. 9-27, 1993. doi:http://dx.doi. org/10.1016/0143-6228(93)90077-E

[30] Nedovic-Budic,Z.,Evaluating theEffectsofGISTechnology:Review ofMethods,JournalofPlanning Literature, 13(3), pp. 284-295, 1999. doi:http://dx.doi.org/10.1177/08854129922092405

[31] Blaschke, Th., Sustainability with GIS? Towards a proactive nature conservation approach. New Developments in GIS, eds J. Johnston \& M. Gomarasca, Ann Arbor, pp. 198-209, 1997.

[32] Bahaire, T. \& Elliott-White M., The application of Geographical Information Systems (GIS) in sustainable tourism planning: A review. International Journal of Sustainable Tourism, 7(2), pp. 159-174, 1999. doi:http://dx.doi.org/10.1080/09669589908667333

[33] Dalumpines, R., Using RS and GIS in developing indicators to support urban transport ecological footprint analysis: the case of Ahmedabad city, India. MSc. Thesis. ITC, The Netherlands, 2008.

[34] Marr J.A., Pascoe T.R. \& Benwell L.G., Interoperable GIS and Spatial Process Modelling. Proc. of the 2nd annual conference of GeoComputation '97 \& SIRC '97, University of Otago: New Zealand, 1997. 